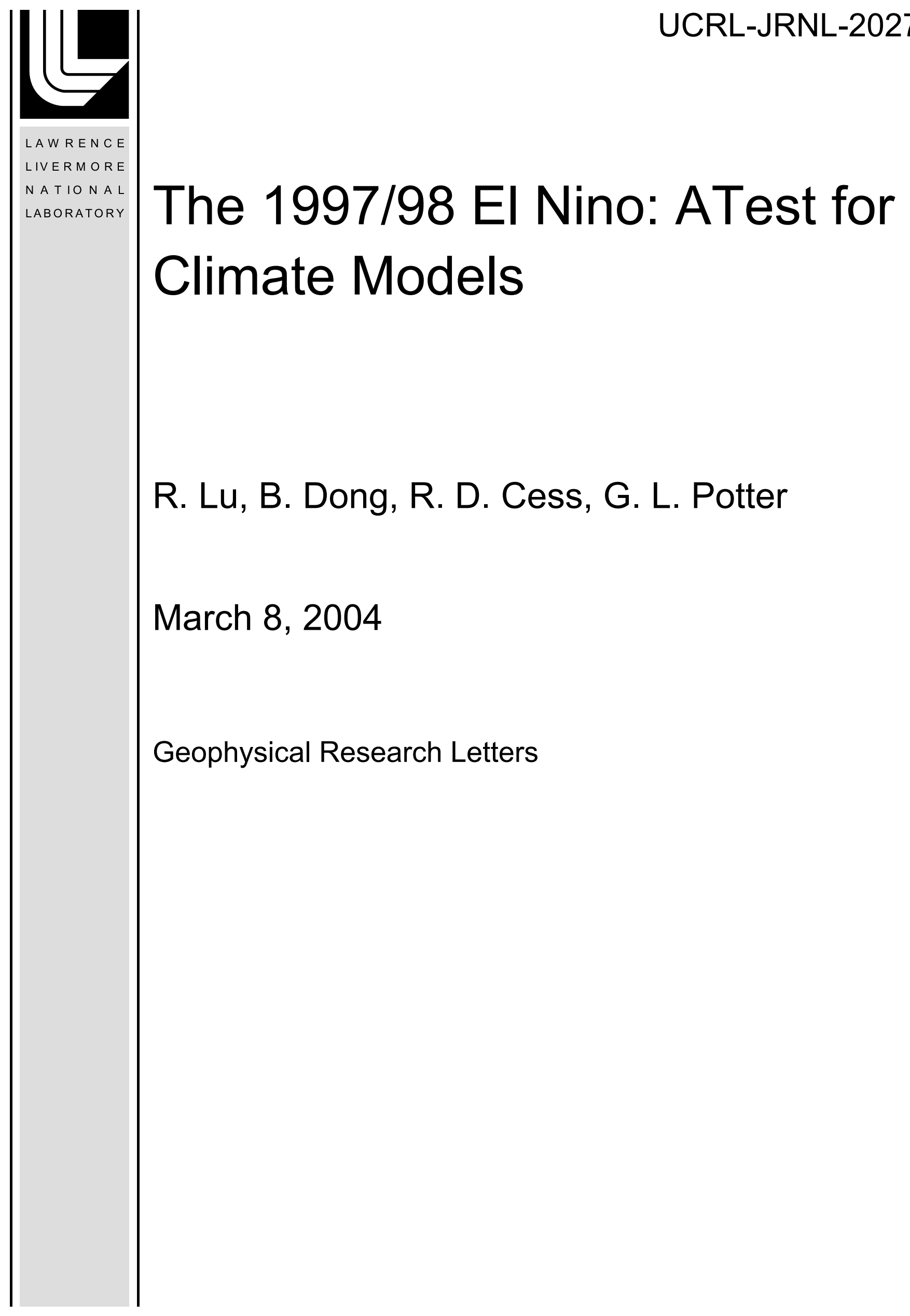


This document was prepared as an account of work sponsored by an agency of the United States Government. Neither the United States Government nor the University of California nor any of their employees, makes any warranty, express or implied, or assumes any legal liability or responsibility for the accuracy, completeness, or usefulness of any information, apparatus, product, or process disclosed, or represents that its use would not infringe privately owned rights. Reference herein to any specific commercial product, process, or service by trade name, trademark, manufacturer, or otherwise, does not necessarily constitute or imply its endorsement, recommendation, or favoring by the United States Government or the University of California. The views and opinions of authors expressed herein do not necessarily state or reflect those of the United States Government or the University of California, and shall not be used for advertising or product endorsement purposes. 


\title{
The 1997/98 EI Niño: A test for climate models
}

\section{Riyu Lu}

Institute of Atmospheric Physics, Chinese Academy of Sciences, Beijing 100080, China

\section{Buwen Dong \\ Hadley Centre for Climate Prediction and Research, Met Office, FitzRoy Road, Exeter EX1 3PB, UK}

\section{Robert D. Cess}

Marine Sciences Research Center, State University of New York at Stony Brook, Stony Brook, New York, 11790, USA

\section{Gerald L. Potter \\ Program for Climate Model Diagnosis and Intercomparison, Lawrence Livermore National Laboratory, Livermore, California, 94550, USA}

\begin{abstract}
Version 3 of the Hadley Centre Atmospheric Model (HadAM3) has been used to demonstrate one means of comparing a general circulation model with observations for a specific climate perturbation, namely the strong 1997/98 El Niño. This event was characterized by the collapse of the tropical Pacific's Walker circulation, caused by the lack of a zonal sea surface temperature gradient during the El Niño. Relative to normal years, cloud altitudes were lower in the western portion of the Pacific and higher in the eastern portion. HadAM3 likewise produced the observed collapse of the Walker circulation, and it did a reasonable job of reproducing the west/east cloud structure changes. This illustrates that the 1997/98 El Niño serves as a useful means of testing cloud-climate interactions in climate models.
\end{abstract}




\section{Introduction}

Cloud-climate interactions comprise one of the greatest uncertainties in attempting to model climate change using general circulation models (GCMs), and there is a need to devise ways of testing such interactions within models. If a GCM is to properly portray long-term climate change, it in turn must replicate cloud changes associated with events occurring on shorter time scales. Recently Cess et al. [2001] demonstrated that the lack of a zonal SST gradient in the tropical Pacific Ocean during the 1997/98 El Niño caused a collapse of the Walker circulation together with enhanced upward motion over the eastern Pacific. This in turn resulted, on average, in lower clouds in the western potion of the tropical Pacific and higher clouds in the eastern portion. The data used to determine these west/east cloud changes consisted of cloud profiling measurements made by the Stratospheric Aerosol and Gas Experiment (SAGE) II, together with cloud-radiative forcing (CRF) as determined for a 5-yr period (19851989) and for the first 4 months of 1998 by the Clouds and the Earth's Radiant Energy System (CERES) instrument on the Tropical Rainfall Measuring Mission (TRMM) Satellite. As emphasized by Cess et al. [2001], these cloud structure changes should serve as a useful test of a GCM, and in the present study we demonstrate this by applying this test to Version 3 of the Hadley Centre Atmospheric Model (HadAM3) [Pope et al., 2000]. Allan et al., [2002] have also compared HadAM3 to ERBE/CERES measurements in the tropical Pacific, and we later place their and our respective studies in perspective. 


\section{Data and Model}

As in Cess et al. [2001], we employ zonal winds from the National Environmental Prediction Center/National Center for Atmospheric Research (NCEP/NCAR) reanalysis [Kistler et al. [2001]. The ERBE/CERES data are likewise the same as used by Cess et al. [2001] and for the same western and eastern study regions as shown in Figure 1. The ERBE TOA measurements are for the first four months (JFMA) of 1985-1989 together with CERES measurements for the first four months of 1998 that represent the strongest period of the 1997/98 El Niño for which CERES data are available (CERES/TRMM data cover January through August 1998).

Two experiments have been performed with HadAM3. One consists of a control, or "normal year", experiment in which climatological sea-surface temperatures (SSTs), averaged over 30 years from 1961 to 1990 [Smith and Reynolds, 1988], were prescribed. The other experiment, the "El Niño" experiment, used observed SSTs from June 1, 1996 to August 31, 1998 [Reynolds and Smith, 1994]. These two integrations were different only in their initial conditions, which were taken from the end of spin-up integrations. For the normal-year integration, the spin-up with climatological SSTs lasted 1.5 years, after which the control experiment was run for one year beginning on December 1. For the El Niño experiment the spin-up, using observed SSTs, was from June 1, 1996 to December 31, 1996, after which the El Niño experiment was integrated from January 1, 1997 to August 31, 1998. Each experiment consists of the average of an ensemble of 10 runs. 


\section{Analysis}

A major change in the atmospheric circulation over the tropical Pacific, as caused by the $1997 / 98$ El Niño, was the virtual collapse of the Walker circulation [Bell et al. 1999; Cess et al., 2001], and this in turn caused the west/east changes in cloud structure noted by Cess et al. [2001] employing both SAGE II cloud profiling and ERBE/CERES TOA radiometric measurements. This collapse of the Walker circulation is demonstrated by comparing the NCEP/NCAR zonal winds in Figure 2c (El Niño) to those in Fig. 2a (normal year). The upward branch of the Walker circulation is centered between $140^{\mathrm{O}} \mathrm{E}$ and $160^{\circ} \mathrm{E}$ (Figure $2 \mathrm{a}$ ), which corresponds to strong convection that produces high clouds in the western region. The downward branch is located to the east of $160^{\circ} \mathrm{W}$, with subsidence air suppressing deep convection and producing shallow stratus and stratocumulus clouds. The Walker circulation has all but ceased in 1998 (Figure 2c), and the westerlies east of the dateline in the upper troposphere have disappeared. This collapse of the Walker circulation is directly associated with the lack of a zonal SST gradient, and further discussion of this is given in Cess et al. [2001]. Thus a crucial first step in using the 1997/98 El Niño as a test of a GCM is to test if the GCM produces a similar collapse of the Walker circulation, and Figure 2 demonstrates that HadAM3 does a remarkably good job in this regard. This agreement of the model with the NCEP/NCAR horizontal winds is consistent with a related study [Allan et al., 2002] who found agreement between HadAM3 and NCEP/NCAR 500-hPa vertical velocities.

We next consider the interpretation of the ERBE/CERES TOA radiometric flux data in terms of the SW and LW components of cloud-radiative forcing, where 


\section{$\mathrm{SW} \mathrm{CRF}=\mathrm{R}_{\mathrm{C}}-\mathrm{R}$}

with $\mathrm{R}$ denoting the TOA all-sky reflected $\mathrm{SW}$ and $\mathrm{R}_{\mathrm{C}}$ that for clear skies, while

$$
\mathrm{LW} \mathrm{CRF}=\mathrm{F}_{\mathrm{C}}-\mathrm{F}
$$

where $\mathrm{F}$ and $\mathrm{F}_{\mathrm{C}}$, respectively, denote the all-sky and clear-sky TOA emitted LW. Figure 3 compares the ERBE/CERES measurements to HadAM3, for both the western and eastern study regions, and for SW CRF, LW CRF and the ratio N, where

$$
\mathrm{N}=-(\mathrm{SW} \text { CRF/LW CRF) }
$$

Here normal year refers to a four year average; 1985-1989 with 1987 excluded because of the modest El Niño that occurred during that year. These data are from ERBE, while the 1998 measurements are from CERES. All are 4-month means (JFMA) for the respective years.

We begin with an explanation of the ERBE measurements. That $\mathrm{N} \approx 1$ for the western region during a normal year (Figure 3b) represents the well know nearcancellation between the SW and LW components of CRF [Kiehl and Ramanathan, 1990; Kiehl, 1994; Hartmann et al. 2001]. Since SW CRF and LW CRF are both, to first order, linearly proportional to cloud fraction, then the ratio $\mathrm{N}$ is, again to first order, invariant to cloud fraction and thus serves as a measure of average cloud altitude. For example, a decrease in cloud altitude results in a warmer cloud that emits more LW 
radiation that decreases LW CRF and so increases N. Thus Figure $3 \mathrm{~b}$ illustrates that during the El Niño cloud altitudes, on average, decreased in the western region. Figures $3 \mathrm{~d}$ to $3 \mathrm{f}$ show reverse trends for the eastern region as compared to the western region. In particular, the reduction of cloud altitude in the western region (Figure 3b), and the corresponding increase in the eastern region (Figure 3e), are consistent with the independent SAGE II cloud profiling measurements [Cess et al., 2001]. Since our western and eastern regions respectively encompass the ascending and descending branches of the Walker circulation, these west/east reversals in Figure 3 are a direct consequence of the collapse of this circulation in addition to enhanced upward motion in the eastern Pacific caused by a stronger Hadley circulation in the eastern Pacific [Cess et al., 2001].

Similar results are shown in Figure 3 for HadAM3, and the important feature is that, in general, the normal year to 1998 trends for HadAM3 are similar to those for ERBE. For the western region the increase in $\mathrm{N}$ (decrease in cloud altitude) is smaller than for ERBE, whereas for the eastern region the reverse trends are quite similar. In contrast, Allan et al. [2002] find little change in $\mathrm{N}$ between 1998 and normal years for HadAM3 (their Table 2). A plausible explanation for their finding is that they considered the entire tropical and subtropical Pacific extending in latitude from $30^{\circ} \mathrm{S}$ to $30^{\circ} \mathrm{N}$, an area that includes the descending and ascending branches of both the Walker circulation and the Hadley circulation. This makes it difficult to interpret their $\mathrm{N}$ values in terms of changes in atmospheric circulation. In addition, for HadAM3 the greatest changes in $\mathrm{N}$ occur in the northeastern portion of Allan et al.'s study area, producing $\mathrm{N} \approx 3$ near $25^{\mathrm{O}} \mathrm{N}$ and $120^{\circ} \mathrm{W}$ for a normal year, and increasing to $\mathrm{N} \approx 8$ in 1998 . Conversely, in the 
southeastern portion, near $15^{\mathrm{O}} \mathrm{S}$ and $100^{\circ} \mathrm{W}$, the change of $\mathrm{N}$ is in the opposite direction and of nearly the same magnitude. Clearly there are large regional cancellations.

In addition to ERBE and CERES TOA data, Allan et al. [2002] also used data from the first Scanner for Radiation Budget instrument (ScaRaB) which operated during 1994 and 1995 [Kandel et al., 1998]. The ScaRaB data produce the intriguing suggestion that $\mathrm{N}$ for $1994 / 95$ is comparable to that for 1998 , both for their large study area as described above, as well as for the Pacific warm pool $\left(5^{\circ} \mathrm{S}-5^{\circ} \mathrm{N}, 145^{\circ} \mathrm{E}-165^{\circ} \mathrm{SE}\right)$. This led them to conclude that the elevated values of $\mathrm{N}$ for $1994 / 5$ and 1998 had a similar cause that was unrelated to the 1997/98 El Niño, but was instead the result of decadal variations in the TOA radiation budget [Wielicki et al., 2002]. This, however, would not explain the reduction in $\mathrm{N}$ that we find for 1998 in the eastern region from the ERBE/CERES measurements (Figure 3). Moreover, a recent study employing SAGE II cloud profiling measurements [P.-H. Wang, private communication, 2004] does find a change in cloud structure over the western region for 1994/95, and then returning to normal until the 1997/98 event, but not over the eastern region. A probable cause for the western region change is the 1994/95 El Niño. This is often combined with the 19911993 El Niño and referred to as the 1990-1995 El Niño [Trenberth and Hoar, 1996]. Relative to the normal year (Figure 2a), the NCEP/NCAR horizontal winds for 1995 do show a weakening of the Walker circulation (Figure 4a). In particular, the change in the ascending branch of the Walker circulation could be consistent with the changes in cloud structure as observed by SAGE II over the western region. In 2000 the atmosphere is in its normal dynamical state as shown in Figure $4 \mathrm{~b}$, again suggesting that decadal variations do not explain the cloud structure anomalies during the 1994/95 and 1997/98 
El Niños. So while we agree with the conclusion of Allan et al. [2002] that HadAM3 produced a realistic dynamical response of its atmosphere over the tropical Pacific during the strong 1997/98 El Niño, we disagree with their conclusions concerning associated cloud structure changes.

\section{Summary}

This study has demonstrated, through the use of HadAM3, the utility of using the strong 1997/98 El Niño as one means of testing cloud-climate interactions within a GCM. A crucial first step is to determine if a GCM produces the observed collapse of the Walker circulation, and HadAM3 did a remarkable job of passing this test. The second phase of the test is to compare the model to ERBE/CERES TOA measurements, and the model did produce trends similar to those inferred from the satellite measurements. On average, cloud altitudes decreased over the western Pacific and increased over the eastern Pacific, both caused by the collapse of the model's Walker circulation. We feel this is a useful test to apply to other GCMs.

Acknowledgments. This work was partially supported by the National Natural Science Foundation of China under Grant 40221503 to the Institute of Atmospheric Physics. Buwen Dong was supported by the UK Government Meteorological Research Programme and the HadAM3 simulations were performed when he was at the Centre for Global Atmospheric Modelling (CGAM) funded by the UK Natural Environmental Research Council. This work was also performed under the auspices of the Department of Energy's Office of Science, Biological and Environmental Research through Grants 
DEFG0290ER61063 and DEFG028ER6013 to SUNY Stony Brook and Contract W-

7405-ENG-48 to the UC/Lawrence Livermore National Laboratory, and by the CERES Project through NASA Contract NAS1-981421 to SUNY Stony Brook.

\section{References}

Allan, R. P., A. Slingo, and M. A. Ringler, Influence of dynamics on the changes in tropical cloud radiative forcing during the 1998 El Niño, J. Climate, 15, 19791986, 2002.

Bell, G. D., M. S. Halpert, C. F. Ropelewski, V. E. Kousky, A. V. Douglas, R. C. Schnell, and M. E. Gelman, Climate assessment for 1998, Bull. Am. Meteorol. Soc., 80, S1-S48, 1999.

Cess, R. D., M. H. Zhang, P.-H. Wang, and B. A. Wielicki, Cloud structure anomalies over the tropical Pacific during the 1997/98 El Niño, Geophys. Res. Lett., 28, 4547-4550, 2001.

Hartmann, D. L., L. A. Moy and Q. Fu, Tropical convection and the energy balance at the top of the atmosphere, J. Climate, 14, 4495-4511, 2001.

Kandel, R., et al., The ScaRaB radiation budget data set, Bull. Amer. Meteor. Soc., 77, 765-783, 1998.

Kiehl J. T., On the observed near cancellation between longwave and shortwave cloud forcing in tropical regions, J. Climate, 7, 559-565, 1994.

Kiehl, J. T., and V. Ramanathan, Comparison of cloud forcing derived from Earth Radiation Budget Experiment with that simulated by the NCAR Community climate Model. J. Geophys. Res., 95, 11679-11698, 1990. 
Pope, V. D., M. L. Gallani, P. R. Roundtree, and R. A. Stratton, The impact of new physical parameterizations in the Hadley Centre climate model-HadAM3, Climate Dyn., 16, 123-126, 2000.

Kistler, R. et al., The NCEP-NCAR 50-year reanalysis: Monthly means CD-ROM and documentation, Bull. Amer. Meteor. Soc., 82, 247-267, 2001.

Reynolds, R. W., and T. M. Smith, Improved global sea surface temperature analyses using optimum interpolation, J. Climate, 7, 929-948,1994.

Smith T. M., and R. W. Reynolds, A high-resolution global sea surface temperature climatology for the 1961-90 base period, J. Climate, 11, 3320-3323, 1998.

Trenberth, K. E., and T. J. Hoar, The 1990-1995 El Niño and Southern Oscillation event: Longest on record, Geophys. Res. Lett., 23, 57-60, 1996.

Wielicki B. A., et al., Evidence for large decadal variability in the tropical mean radiative energy budget, Science, 295, 841-844, 2002. 


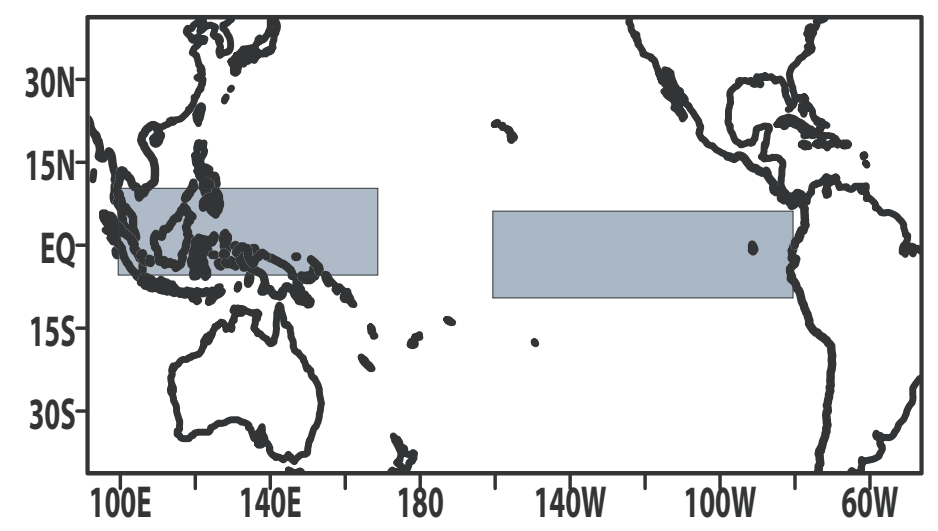

Figure 1. The shaded areas denote the western (5S-10N, 100E-170E) and eastern $(7.5 \mathrm{~S}-7.5 \mathrm{~N}, 80 \mathrm{~W}-160 \mathrm{~W})$ study areas. 

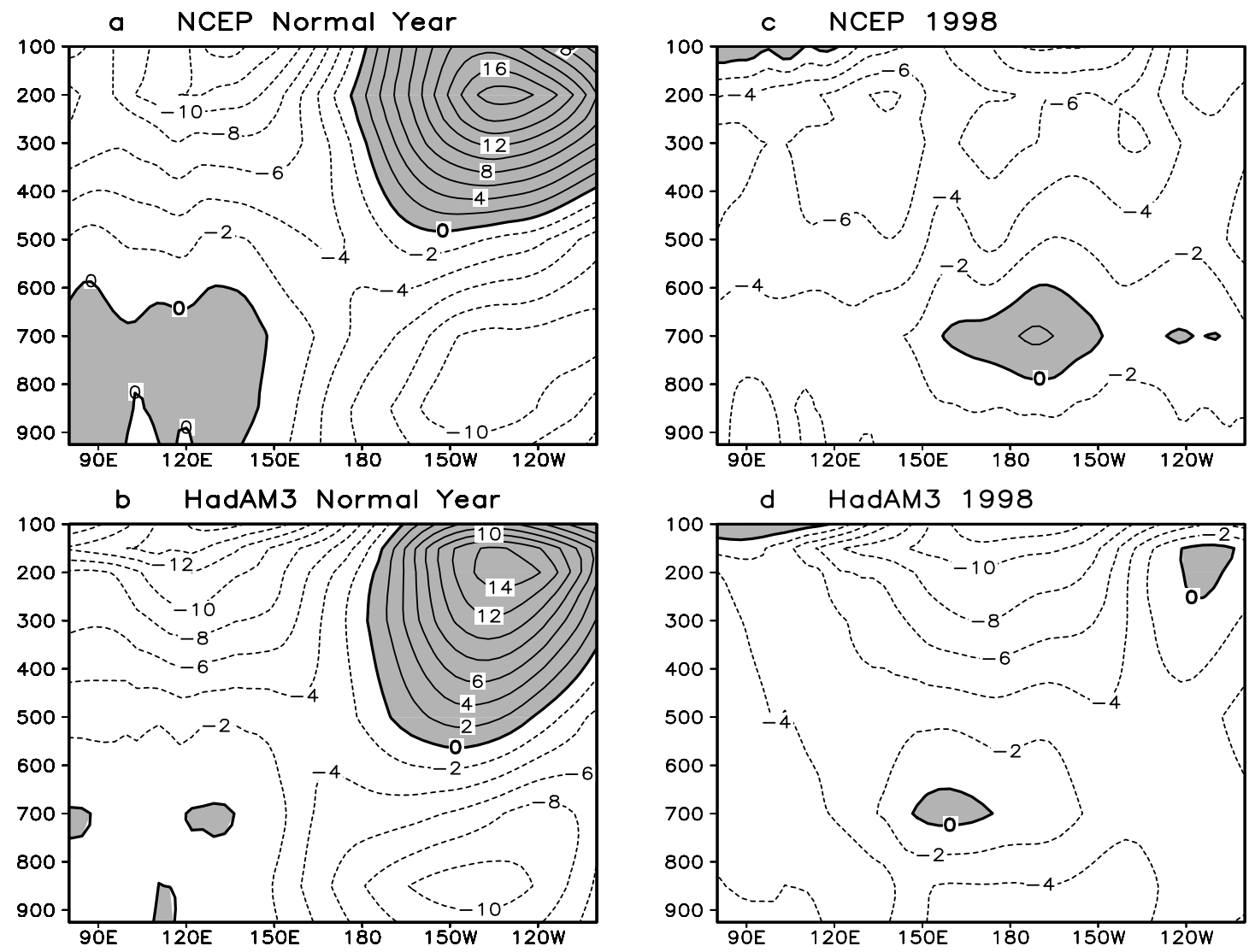

Figure 2. Pressure-longitude cross sections of zonal wind $(\mathrm{m} / \mathrm{s})$ averaged from $5 \mathrm{~S}$ to $5 \mathrm{~N}$ and for 4 months (JFMA). (a) NCEP/NCAR normal year. (b) HadAM3 normal year. (c) NCEP/NCAR 1998. (d) HadAM3 1998. 


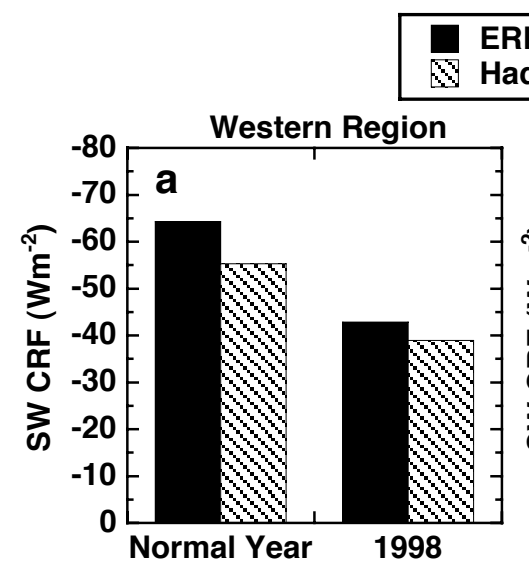

RBE/CERES

HadAM3
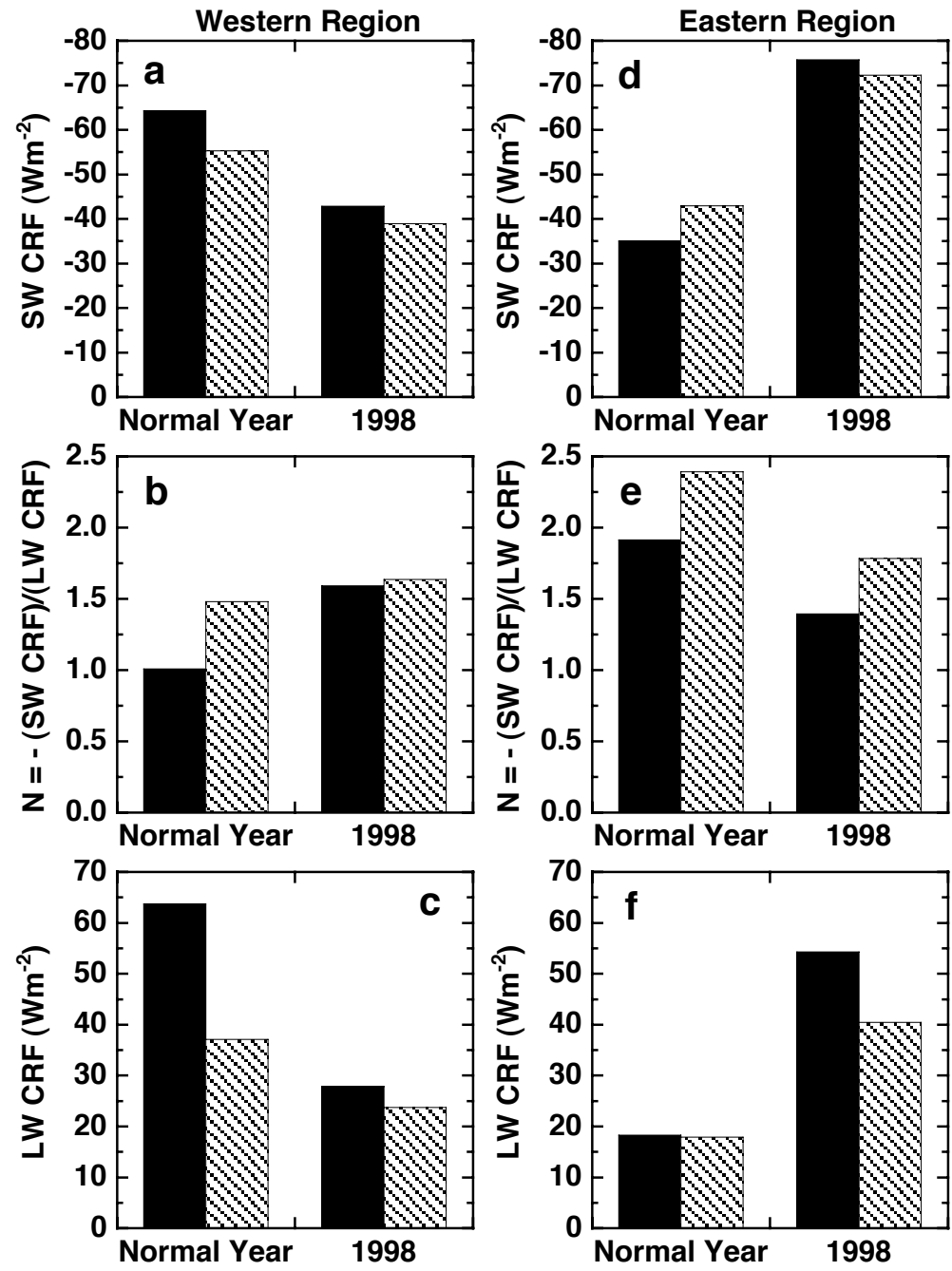

Figure 3. (a-c) Four-month means (JFMA) of SW CRF, $N=-(\mathrm{SWCRF}) / \mathrm{LW}$ CRF) and LW CRF for the western region. (d-e) The same as (a-c) but for the eastern region. 

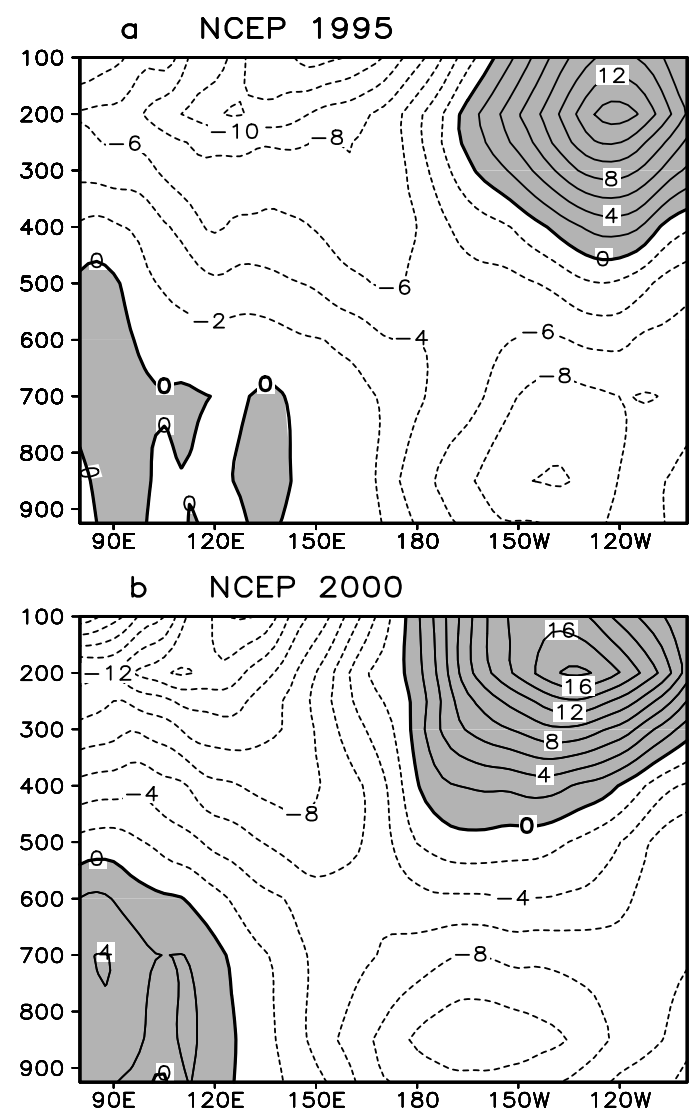

Figure 4. Pressure-longitude cross sections of zonal wind (m/s) averaged from $5 \mathrm{~S}$ to $5 \mathrm{~N}$ and for 4 months (JFMA). (a) NCEP/NCAR for 1995. (b) NCEP/NCAR for 2000. 